Functionalization of synthesized zeolite was done with the sterically hindered AMP. This facilitated the adsorption of $\mathrm{CO}_{2}$ at higher temperatures and also improved adsorption capacity in the presence of moisture, which is otherwise a major concern in case of zeolite for flue gas stream from power plants. Regeneration studies revealed that the adsorption capacity decreased after the second cycle of adsorption. Efforts must now be taken to improve regeneration in the later cycles of adsorption in further research.

Declaration. The authors declare no competing financial interests.

1. https://www.esrl.noaa.gov/gmd/ccgg/trends/ (assessed on 4 June 2019).

2. Luthi, D. et al., High-resolution carbon dioxide concentration record 650,000-800,000 years before present. Nature, 2008, 453, 379-382.

3. Herzog, H. J., Scaling up carbon dioxide capture and storage: from megatons to gigatons. Energ. Econ., 2011, 33, 597-604.

4. Lee, Z. H., Lee, K. T., Bhatia, S. and Rahman, A. M., Postcombustion carbon dioxide capture: evolution towards utilization of nanomaterials. Renew. Sust. Energ. Rev., 2012, 16, 2599-2609.

5. Lee, M. G., Yi, G., Ann, B. J. and Roddick, F., Conversion of coal fly ash into zeolite and heavy metal removal. Korean J. Chem. Eng., 2000, 17, 325-331.

6. Ahmed, M. A., Shahnawaz, M., Siddiqui, M. F. and Khan, Z. H., A statistical review on the current scenario of generation and utilization of fly ash in India. Int. J. Curr. Eng. Technol., 2014, 4, 2434-2438.

7. Adamczyk, Z. and Bialecka, B., Hydrothermal synthesis of zeolites from polish coal fly ash. Pol. J. Environ. Stud., 2005, 14, 713-719.

8. Ma, W., Brown, P. W. and Komarneni, S., Characterization and cation exchange properties of zeolite synthesized from fly ashes. J. Mater. Res., 1998, 13, 3-7.

9. Shigemoto, N. and Hayashi, H., Selective formation of $\mathrm{Na}-\mathrm{X}$ zeolite from coal fly ash by fusion with sodium hydroxide prior to hydrothermal reaction. J. Mater. Sci., 1993, 28, 4781-4786.

10. Rayalu, S. S., Udhoji, J. S., Munshi, K. N. and Hasan, M. Z., Highly crystalline zeolite A from fly ash of bituminous and lignite coal combustion. J. Hazard. Mater., 2001, 88, 107-121.

11. Rayalu, S., Meshram, S. U. and Hasan, M. Z., Highly crystalline faujasitic zeolite from fly ash. J. Hazard. Mater., 2000, 77, 123131

12. Dindi, A., Quang, D. and Abu-Zahra, M. R. M., $\mathrm{CO}_{2}$ adsorption testing on fly ash derived cancrinite-type zeolite and its aminefunctionalized derivatives. Environ. Prog. Sust. Energ., 2019, 38, 77-78.

13. Belviso, C., State-of-the-art applications of fly ash from coal and biomass: a focus on zeolite synthesis processes and issues. Prog. Energ. Combust. Sci., 2018, 65, 109-135.

14. Oliveira, J. A., Cunha, F. A. and Ruotolo, L. A. M., Synthesis of zeolite from sugarcane bagasse fly ash and its application as a low-cost adsorbent to remove heavy metals. J. Clean. Prod., 2019, 229, 956-963.

15. Dindi, A., Quang, V. D., Vega, L. F., Nashef, E. and Abu-Zahra, M. R. M., Applications of fly ash for $\mathrm{CO}_{2}$ capture, utilization, and storage. J. $\mathrm{CO}_{2}$ Util., 2019, 29, 82-102.

16. Bougie, F. and Iliuta, M. C., Sterically hindered amine-based absorbents for the removal of $\mathrm{CO}_{2}$ from gas streams. J. Chem. Eng. Data, 2012, 57, 635-669.
17. Kim, W., Chae, W., Kwon, S., Kim, K., Lee, H. and Kim, S., Effect of dry grinding of pyrophyllite on the hydrothermal synthesis of zeolite Na-X and Na-A. Mater. Trans. JIM, 2014, 55, 14881493.

18. Hui, H., Gao, J., Wang, G., Liu, P. and Zhang, K., Effects of $\mathrm{Na}$ and $\mathrm{K}$ ions on the crystallization of low silica $\mathrm{X}$ zeolite and its catalytic performance for alkylation of toluene with methanol. $J$. Braz. Chem. Soc., 2014, 25, 65-74.

19. Sing, K. S. W., Everett, D. H., Haul, R. A. W., Moscou, L., Pierotti, R. A., Rouquerol, J. and Siemieniewska, T., Reporting physisorption data for gas/solid systems with special reference to the determination of surface area and porosity. Pure Appl. Chem., 1985, 57, 603-619.

20. Su, F., Lu, C., Kuo, S. C. and Zeng, W., Adsorption of $\mathrm{CO}_{2}$ on amine-functionalized Y-type zeolites. Energ. Fuel, 2010, 24, $1441-1448$.

ACKNOWLEDGEMENTS. We thank the Director, CSIR-NEERI, Nagpur for providing research facilities, and the International Scientific Partnership Program at King Saud University, Riyadh for funds through ISPP\# 0057 Grant (CSIR-NEERI/KRC/2019/JUNE/EMD-ERMD/1).

Received 9 August 2019; revised accepted 20 May 2020

doi: $10.18520 / \mathrm{cs} / \mathrm{v} 119 / \mathrm{i} 1 / 123-128$

\section{Landsat 8-based surface temperature anomaly and hydrocarbon prospectivity: a study in part of Assam-Arakan Fold Belt, North East India}

\author{
Santosh Garain ${ }^{1}$, Debashis Mitra ${ }^{2}$ and \\ Pranab Das ${ }^{3, *}$
}

${ }^{1}$ Oil and Natural Gas Corporation Limited, Assam-Arakan Fold Belt Exploratory Asset, Silchar 788 026, India

${ }^{2}$ Indian Institute of Remote Sensing, 4, Kalidas Road,

Dehradun 248 001, India

${ }^{3}$ Department of Applied Geology, Indian Institute of Technology (Indian School of Mines), Dhanbad 826 004, India

Subsurface hydrocarbon reservoirs act as effective thermal barriers to the Earth's heat flow from the interior to the surface. As a result, a positive thermal anomaly below a hydrocarbon reservoir and a negative thermal anomaly on the surface above the reservoir are observed. The use of remote sensing satellite images is a rapid, cost-effective and accurate method of determining land surface temperature of a region. The present study uses recent Landsat 8 operational

*For correspondence. (e-mail: pranab@iitism.ac.in) 
land imager-thermal infrared sensor images to detect land surface temperature distribution in a part of the Assam-Arakan Fold Belt, North East India, using a single-channel algorithm. Two anomalous negative surface temperature zones to the south of the study area are found to be important. High-resolution Landsat 8 panchromatic image, surface geological map, NDVI map and SRTM data rule out the effects of artefacts, urban settlements, and variations in lithology, vegetation or topography on these anomalous zones. The superimposition of the surface temperature map over the previously determined hydrocarbon prospect map reveals that these negative surface temperature anomalies lie over two significant hydrocarbon prospect zones. Thus, the effect of subsurface petroleum reservoirs is evident on the land surface temperature distribution of the area. Therefore, satellite image-based land surface temperature mapping can be used as an aid in detecting potential target areas for hydrocarbon exploration in the entire basin.

Keywords: Hydrocarbon exploration, satellite images remote sensing, surface temperature anomaly.

IT is well established that the temperature of the Earth increases with depth. Thus, heat flows from the Earth's interior to the surface, which is evident from wells drilled into the Earth's crust ${ }^{1}$. The heat generated in the subsurface flows through the solid crust, primarily in the form of conduction ${ }^{2}$. Thus, depending upon the thermal conductivities of the subsurface rocks, the temperatures of the Earth's surface will vary. For example, in case of shale beds that have low thermal conductivities, the subsurface heat cannot escape through and accumulates below them ${ }^{1}$. Thus, an increase in temperature below the shale strata and a low temperature above the strata are observed. On the other hand, salt beds, being highly conductive, pass the heat easily to the surface and cause an increase in the surface temperature ${ }^{1}$. Hydrocarbons are considered as thermally more insulative than other common Earth materials, and hydrocarbons along with connate water act as a greater thermal barrier than hydrocarbons alone, which causes an increase in temperature below the zone of hydrocarbon accumulation and a decline in temperature above the petroleum reservoirs ${ }^{3}$. Thus, a negative land surface temperature (LST) anomaly is observed over the hydrocarbon reservoirs ${ }^{3}$. Several studies have indicated that surface temperature anomalies exist over the oil or gas fields and LST mapping can help locating subsurface hydrocarbon deposits ${ }^{4-7}$. Measurement of surface temperature over a region by field surveying is a difficult task because of differences in many inherent factors like diurnal variation, local surface moisture, etc. ${ }^{6}$. Satellite-based remote sensing, however, overcomes these difficulties by collecting data within a few minutes in a stable condition ${ }^{6}$ and can be effectively used to determine even the subtle variations in LST rapidly, cost-effectively and accurately. The regions of negative thermal anomalies, excluding the effects of artefacts (urban areas, roads, etc.), water bodies (lakes, canals and wet fields), ground vegetation, topography, and lithology may be considered as possible targets for further detailed hydrocarbon exploration ${ }^{6}$. In a study over Cambay Basin in India, it was found that the ASTER-based LST map exhibits preferential clustering of anomalous cooler pixels over the known oil fields ${ }^{6}$. In a similar study in the same basin, using ASTER night-time data, it was proved that low-temperature anomalies exist over the oil fields ${ }^{7}$.

The present study utilizes Landsat 8 (OLI-TIRS; Operational Land Imager-Thermal Infrared Sensor) images to calculate LST over a part of the Assam-Arakan Fold Belt (AAFB) in North East India using a single-channel algorithm. The superimposition of the LST map over the previously detected hydrocarbon prospect map of the same area shows distinct negative thermal anomalies over the two significant hydrocarbon prospects. The study, thus, indicates that analysis of satellite-based land surface thermal anomalies may have the potential in locating hydrocarbon prospects in the entire basin.

The exploration of hydrocarbons by conventional methods like $2 \mathrm{D}$ or $3 \mathrm{D}$ seismics, exploratory well-drilling, etc. is costly and time-consuming and, therefore, cannot be used indiscriminately over the sizeable areal extent of a sedimentary basin. The use of unconventional remote sensing techniques offers more help in delineating the prospective targets for hydrocarbons in the preliminary stage of exploration. The primary objective of this study is to verify the correlation between the Landsat 8-based surface temperature distributions and the occurrence of subsurface hydrocarbon reservoirs in the study area. The result of the study will, therefore, may help find primary prospective areas for hydrocarbons and in reducing the exploration cost.

The study area lies in the southernmost part of the AAFB around Cachar district, Assam, NE India (Figure $1 a)$. Geographically, the study area is bounded by the $24^{\circ} 31^{\prime} \mathrm{N} / 24^{\circ} 57^{\prime} \mathrm{N}$ and $92^{\circ} 37^{\prime} \mathrm{E} / 93^{\circ} 07^{\prime} \mathrm{E}$, covering an area of approximately $2400 \mathrm{sq}$. $\mathrm{km}$. Topographically, the area is surrounded by hilly forested terrain to the north, east and south. The remaining part of the study area is covered by alluvial plains of River Barak and its tributaries, with intermittent small hillocks. The region is characterized by heavy rainfall, with an average annual rainfall of more than $3000 \mathrm{~mm}$. A natural colour composite map of the study area of Landsat 8 (4-3-2, RGB space) is presented in Figure $1 b$, to show the vegetation and land cover.

AAFB is one of the oldest petroliferous basins of India with several oil and gas-producing fields. Though the AAFB basin is considered to have been endowed with substantial hydrocarbon resources, it is still underexplored due mainly to poor understanding of the subsurface configuration arising out of the tectonic complexities $^{8}$. 


\section{RESEARCH COMMUNICATIONS}

Geologically, the AAFB basin is characterized by a series of NNE-SSW trending narrow and elongated plunging anticlines separated by broad flat synclines. The basin shows progressive structural complexities from west to east ${ }^{9,10}$. It comprises a thick succession of clastic sediments with ages ranging from Palaeocene to Recent ${ }^{8}$. Figure 2 shows a surface geological map of the study area (adapted from refs 11, 12).

Landsat 8 OLI-TIRS images of the study area were thoroughly searched, and a recently acquired clear scene with least cloud cover was downloaded from the USGS EROS (United States Geological Survey-Earth Resources Observation and Science) Data Center (https://earthexplorer.usgs.gov.) with the specifications depicted in Table 1.

To determine LST, three separate bands - band 4 (red), band 5 (near-infrared) and band 10 (thermal infrared sensor

(b)


Figure 1. $\boldsymbol{a}$, Geographical location of the study area. $\boldsymbol{b}$, Natural colour composite map of the study area formed by Landsat 8 bands 4-32 in RGB space.
(TIRS)) of Landsat 8 data were used. It is important to mention here that though Landsat 8 has two TIRS bands (bands 10 and 11) suitable for determining LST, following the 2014 USGS notice, only band 10 has been used to calculate LST here. The band images were already geometrically corrected, but were in 16-bit unsigned digital number (DN) values. The single-channel algorithm was followed to convert these DN values into $\mathrm{LST}^{13,14}$. The followings steps were used for LST calculation.

(i) Determination of top of atmospheric (TOA) spectral radiance. This was done using the formula ${ }^{15}$

$$
L_{\lambda}=M_{\mathrm{L}} * Q_{\text {cal }}+A_{\mathrm{L}},
$$

where $L_{\lambda}$ is the spectral radiance, $M_{\mathrm{L}}$ the radiance multiplicative scaling factor for band 10 and is 0.0003342 as

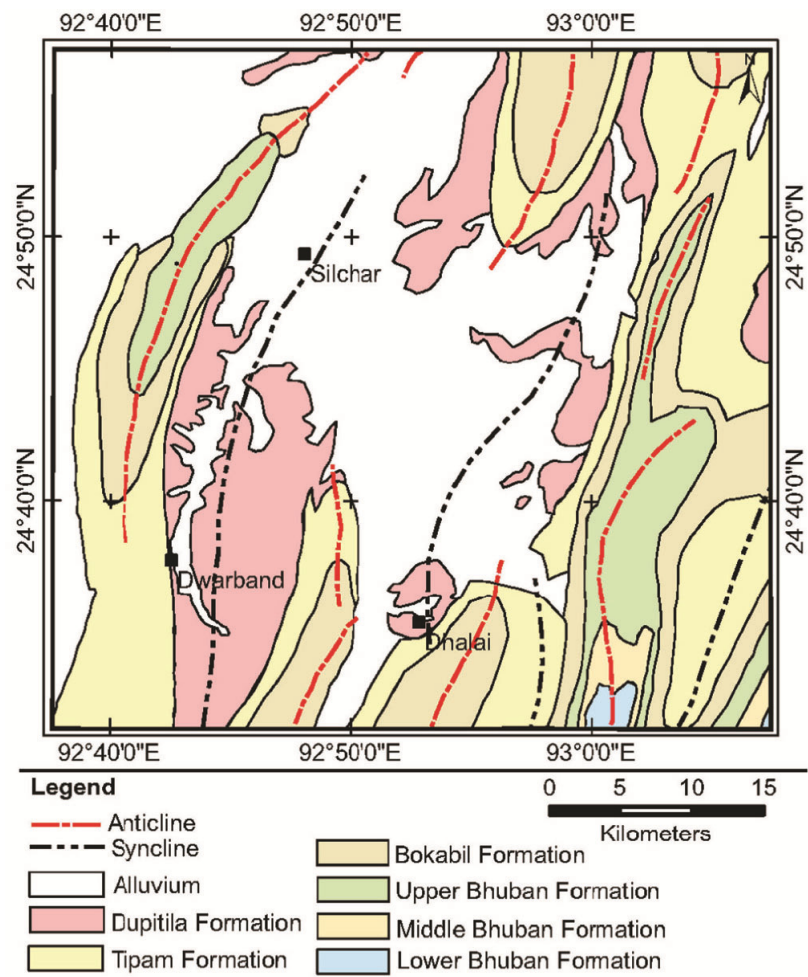

Figure 2. Surface geological map of the study area (adapted from refs $11,12)$.

Table 1. Specifications of Landsat 8 scene for the study area

\begin{tabular}{ll}
\hline Path/row & \multicolumn{1}{c}{$136 / 43$} \\
\hline Date of acquisition & 29 January 2018 \\
Scene centre time & $04: 18: 09.43(\mathrm{GMT})$ \\
Cloud cover & 0.11 \\
Sun azimuth & 146.28628095 \\
Sun elevation & 40.30336560 \\
Map projection & UTM \\
Datum & WGS 84 \\
UTM zone & +46 \\
\hline
\end{tabular}


specified in the metadata of the image, $Q_{\text {cal }}$ the level-1 pixel value of band 10 in $\mathrm{DN}$ and $A_{\mathrm{L}}$ is the radiance additive scaling factor for band 10 and is 0.10 as specified in the metadata of the scene.

(ii) Determination of at-sensor or brightness temperature (BT). BT is the effective temperature viewed by the satellite under unit emissivity. The conversion of TOA radiance to $\mathrm{BT}\left({ }^{\circ} \mathrm{C}\right)$ was done as follows

$$
\mathrm{BT}=\frac{K_{2}}{\ln \left(\frac{K_{1}}{L_{\lambda}}+1\right)}-273.15
$$

where $K_{1}$ and $K_{2}$ are band-specific thermal conversion constants with values 774.8853 and 1321.0789 respectively, as specified in the metadata of the scene.

(iii) Calculation of normalized difference vegetation index (NDVI). The 16-bit DN values of band 4 (red) and band 5 (infrared) were converted into TOA reflectance $(R)$ using following formula ${ }^{15}$

$$
R=\frac{Q_{\mathrm{cal}} * M p+A p}{\sin \theta},
$$

where $Q_{\text {cal }}$ is the quantized and calibrated DN value of the band, $M_{\mathrm{p}}$ is the band-specific multiplicative rescaling factor, $A_{\mathrm{p}}$ is the additive rescaling factor and $\theta$ is the sun elevation (deg). The NDVI was calculated as follows:

$$
\mathrm{NDVI}=\frac{(R 5-R 4)}{(R 5+R 4)}
$$

where $R 5$ and $R 4$ are the reflectance values of band 5 and band 4 respectively.

(iv) Calculation of the proportion of vegetation $\left(P_{\mathrm{V}}\right)$. The proportion of vegetation was calculated using the following formula

$$
P_{\mathrm{V}}=\left(\frac{(\mathrm{NDVI}-\mathrm{NDVIs})}{(\mathrm{NDVIV}-\mathrm{NDVIs}}\right)^{2}
$$

where NDVIs and NDVIv are the NDVI values of soil with no vegetation and densely vegetated areas respectively. The value of NDVIs is taken as 0.20 and NDVIv as 0.5 taken as global values (ref. 16).

(v) Calculation of land surface emissivity LSE $(\varepsilon)$.

While determining LSE, the following conditions were considered. (a) When NDVI $<0$, the object is classified as water, and LSE is taken as 0.991. (b) when $0.20<\mathrm{NDVI} \geq 0$, the object is classified as bare soil, and
LSE is taken as 0.966. (c) When NDVI $>0.50$, the objects is described as dense vegetation, and LSE is taken as 0.973 . (d) When $0.50 \leq \mathrm{NDVI} \geq 0.20$, the following equation is used.

$$
\varepsilon=\varepsilon_{\mathrm{v}} * P_{\mathrm{V}}+\varepsilon_{\mathrm{s}}\left(1-P_{\mathrm{V}}\right)+C_{\lambda}
$$

where $\varepsilon_{\mathrm{v}}$ is the emissivity of the vegetation which is equal to 0.973 for Landsat 8 band $10, \varepsilon_{\mathrm{s}}$ the emissivity of the soil which equal to 0.966 for Landsat 8 band 10 , and $C_{\lambda}$ is the surface roughness which is taken as 0.005 (ref. 17).

(vi) Calculation of LST $\left({ }^{\circ} \mathrm{C}\right)$ : LST was calculated using the following equation

$$
\mathrm{LST}=\left[\mathrm{BT} /\left\{1+\left(\lambda^{*} \mathrm{BT} / r\right) * \ln (\varepsilon)\right\}\right]
$$

where $\lambda$ is the average wavelength of Landsat 8 band 10 which is equal to $10.895 \mu \mathrm{m}$ and $r$ is equal to $1.4388 \times$ $10^{-2} \mathrm{mK}$.

All the above calculations were performed in ArcMap using the Raster calculator tool. Figure 3 shows the Landsat 8 image-derived LST map of the study area.

The Landsat 8-based LST map of the study area was analysed for the influence of artefacts and urban settlements by identifying objects with the help of highresolution Landsat 8 panchromatic band (Figure 4) and Google Earth images. The urban settlements (urban heat islands) were observed to be characterized by higher LST. For example, over the populated Silchar town, LST was around $21^{\circ} \mathrm{C}$. The metalled roads also depicted higher surface temperature. Again, as evident from the TOAcorrected NDVI map (Figure 5), the northern, eastern and southern parts of the study area were covered by dense vegetation. These vegetated areas appear to have low surface temperature $\left(17^{\circ} \mathrm{C}\right.$ or less). Also, the scattered vegetated areas to the west of the study area showed low surface temperature distribution. As the image was acquired in the daytime, it is evident that the land surfaces show higher temperatures than that of the water bodies. The Barak River flowing in the central part of the image having negative NDVI values showed clear low LST distribution (about $18^{\circ} \mathrm{C}$ ) compared to its surrounding land surfaces (about $21^{\circ} \mathrm{C}$ ).

To study the variation of LST with topography in the study area, the LST map was compared with a highresolution Shuttle Radar Topography Mission (SRTM) image (Figure 6). The SRTM image clearly shows topographical highs to the northern, eastern and southern parts, which are characterized by low LST distribution. The central part of the image comprises plain lands with almost uniform height.

The LST map of the study area was superimposed on the satellite image-derived hydrocarbon microseepage prospect map of the same area generated previously ${ }^{18}$. The superimposition revealed two prospective areas for 


\section{RESEARCH COMMUNICATIONS}

hydrocarbons (A and B, Figure 3) with conspicuous low LST. The average surface temperature of prospects A and $\mathrm{B}$ was $18.59^{\circ} \mathrm{C}$ and $18.60^{\circ} \mathrm{C}$ respectively. Three different areas representing non-prospective hydrocarbon regions
(C-E, Figure 3) having the same type of landforms as those of the prospective areas (A and B) were also marked for comparison. The LST data showed that average surface temperature of the hydrocarbon non-prospective

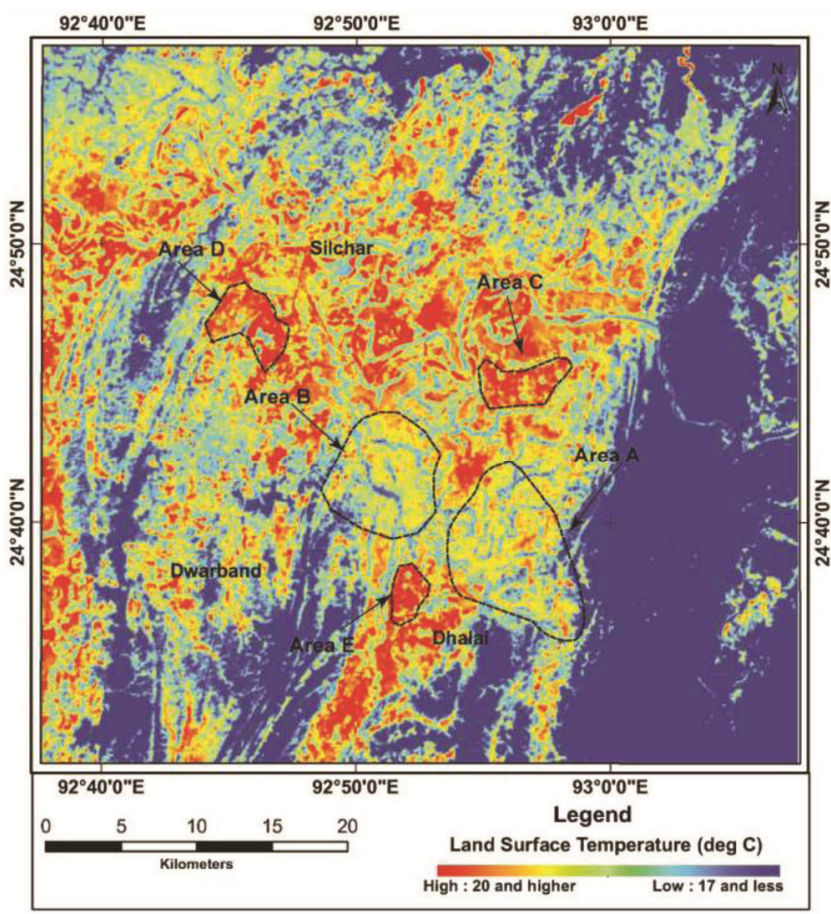

Figure 3. Land surface temperature distribution map of the study area.

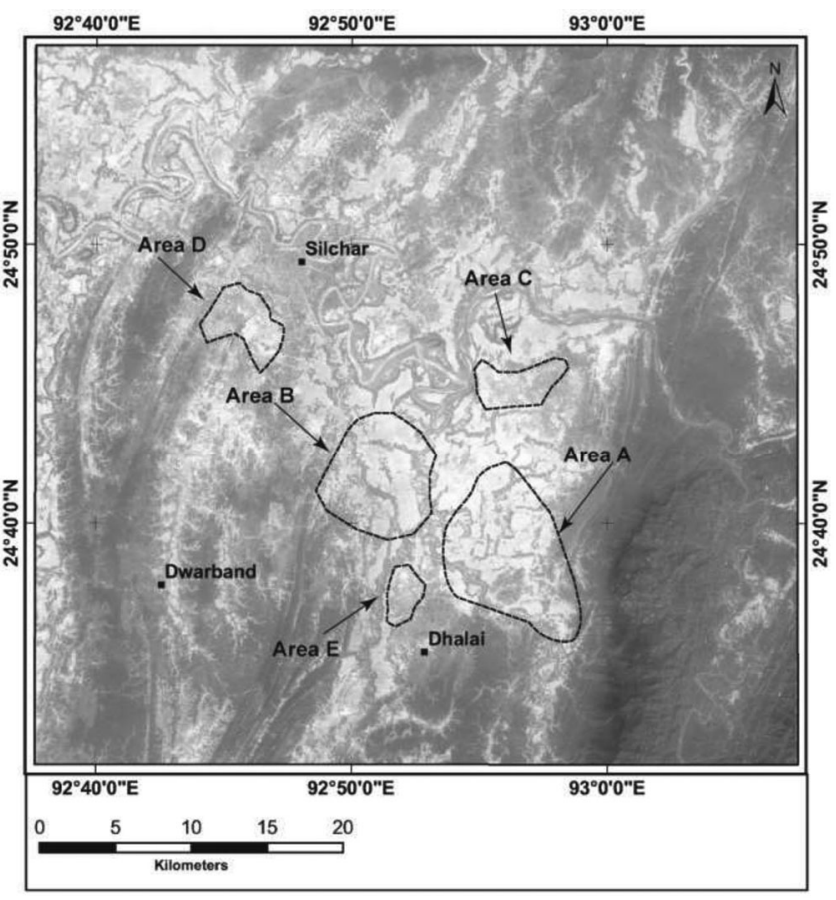

Figure 4. Landsat 8 panchromatic image ( $15 \mathrm{~m}$ resolution) of the study area.

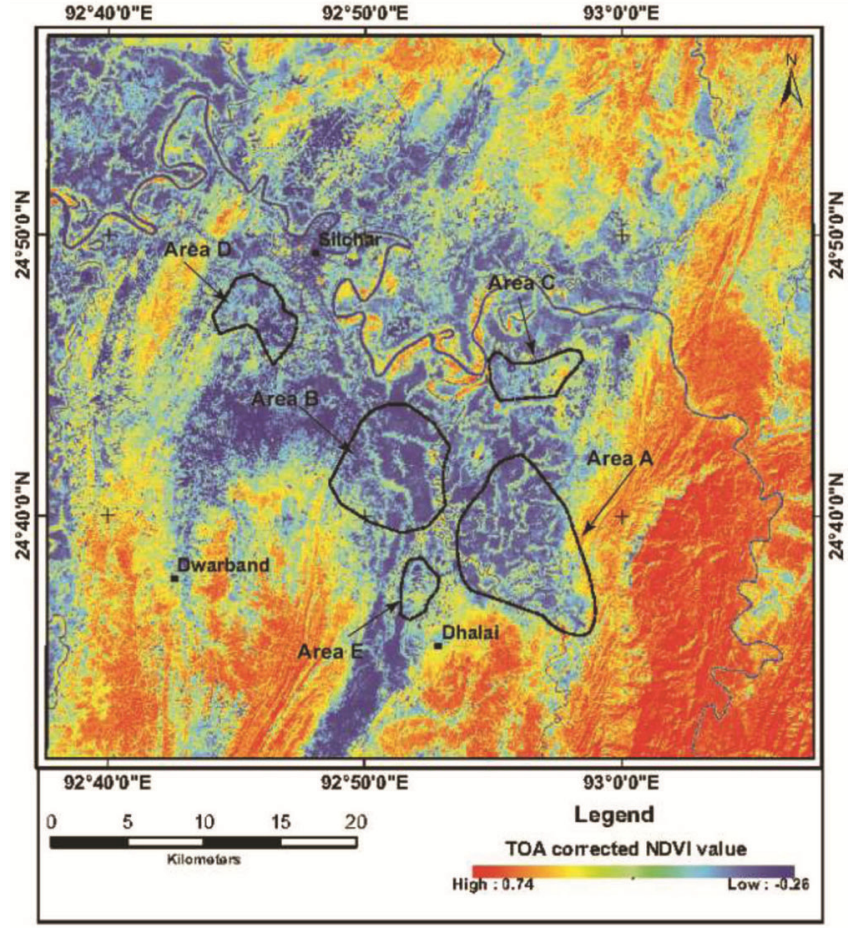

Figure 5. Top of atmosphere (TOA)-corrected NDVI map of the study area.

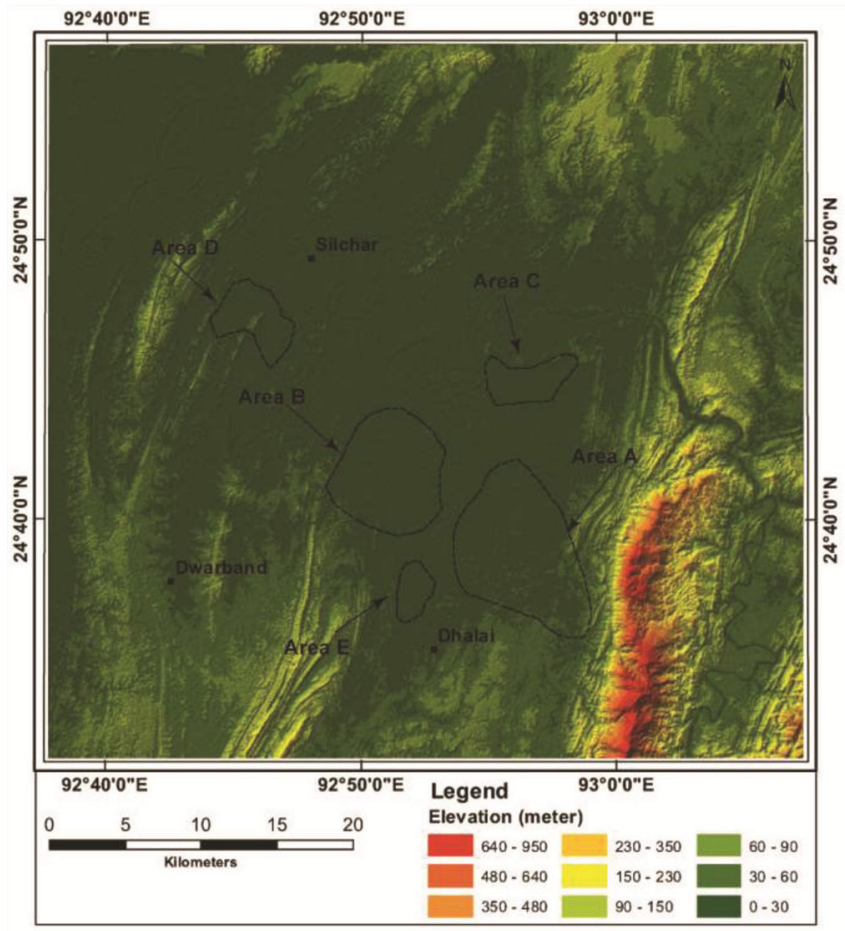

Figure 6. Shuttle radar topography mission image of the study area. CURRENT SCIENCE, VOL. 119, NO. 1, 10 JULY 2020 


\section{RESEARCH COMMUNICATIONS}

areas, viz. C, D and E was $19.61^{\circ} \mathrm{C}, 19.64^{\circ} \mathrm{C}$ and $19.87^{\circ} \mathrm{C}$ respectively. Thus, the hydrocarbon prospect areas have about $1{ }^{\circ} \mathrm{C}$ less surface temperature than that of the nonprospect areas. The surface geological map of the area shows that all these hydrocarbon prospective as well as non-prospective areas are located on the same alluvium plains of Barak River. Again, the SRTM image reveals no variation in topographic altitude among the prospective and non-prospective areas. Also, the NDVI map reveals that the areas are characterized by the same type of vegetation densities. The panchromatic image of the area rules out human or urban activities over the anomalous regions. Therefore, the observed negative thermal anomalies over the hydrocarbon prospect areas may be attributed to the occurrence of subsurface hydrocarbon reservoirs.

Subsurface hydrocarbon accumulation causes negative thermal anomalies on the land surfaces over them. Satellite images can help detect such subtle thermal anomalies in a rapid and cost-effective manner and consequently assist in hydrocarbon exploration, at least in the preliminary stage. The present study carried out in a preestablished hydrocarbon prospect area indicates that the average LST over two prominent hydrocarbon prospect areas is about $1^{\circ} \mathrm{C}$ less than that of the non-hydrocarbonbearing areas. Therefore, this study concludes that satellite-based surface temperature anomalies can be utilized as an effective unconventional tool to target potential prospect areas for hydrocarbons in the entire AAFB and this may help in reducing the cost of hydrocarbon exploration.

Conflicts of interest: The authors declare that they do not have any conflicts of interest.

1. Rider, M., The Geological Interpretation of Well Logs, RiderFrench Consulting Ltd., Scotland, UK, 2002, 2nd edn.

2. Beardsmore, G. R. and Cull, J. P., Crustal Heat Flow: A Guide to Measurement and Modelling, Cambridge University Press, Cambridge, UK, 2001, 1st edn.

3. Fons, L., Temperature method can help locate oil, gas deposits. Oil Gas J., 1999, 97(15), 58-64.

4. Gorny, V. I., Kritsuk, S. G., Latipov, I. S. and Tronin, A. A., Terrestrial heat flux measuring and geothermal zoning for regional and petroleum geology on the base of satellite IR-thermal survey (STS). In Proceedings of the Eleventh Thematic Conference on Geologic Remote Sensing, Las Vegas, Nevada, USA, 1996, vol. 1, pp. 594-605.

5. Hook, S. J., Abbott, E. A., Grove, C., Kahle, A. B. and Palluconi, F., Use of multispectral thermal infrared data in geological studies. In Remote Sensing for the Earth Sciences, Manual of Remote Sensing (ed. Rencz, A. N.), John Wiley, New York, USA, 1999, 3rd edn.
6. Gupta, R. P., Chakraborty, R. and Awasthi, A. K., Satellite data can cost-effectively show oil field thermal anomalies. Oil Gas J., 2009, 107, 34-36.

7. Majumdar, T. J., Mitra, D. S. and Nasipuri, P., Study of surface temperature anomalies over the oil fields in the Cambay Basin, India using ASTER night time data. Int. J. Geoinformat., 2010, 6(1), 55-64.

8. Chatterjee, S. M., Deb, A., Rao, C. V., Reddy, P. K., Sanyal, A. and Yadagiri, K., Triangle zone geometry in Cachar thrust-fold belt, India. In Society of Exploration Geophysicists, New Orleans Annual Meet, New Orleans, 2006, vol. 76, pp. 1118-1122.

9. Ganguly, S., Geology and hydrocarbon prospects of Tertiary succession of the Tripura-Cachar-Mizoram region. Pet. Asia J., 1983, 1, 105-109.

10. Ganguly, S., Stratigraphy, sedimentation and hydrocarbon prospects of the Tertiary succession of Tripura and Cachar (Assam). Indian J. Geol., 1993, 65, 145-180.

11. Kamaraju, A. V. V. S., Modeling concealed structures of Cachar fold belt integrating seismic, geologic and Landsat imageries with special reference to Bhubandar field - Assam and Assam - Arakan Fold belt, India. In 8th Biennial International Conference and Exposition on Petroleum Geophysics, Hyderabad, 2010.

12. Mazumder, S., Adhikari, K., Mitra, D. S., Mahapatra, S. and Pangtey, K. K., A neotectonic based geomorphic analysis using remote sensing data to delineate potential areas of hydrocarbon exploration: Cachar area, Assam. J. Geol. Soc. India, 2016, 88, 1-11.

13. Avdan, U. and Jovanovska, G., Algorithm for automated mapping of land surface temperature using Landsat 8 satellite data. J. Sensing, 2016, 1-8; doi:org/10.1155/2016/1480307.

14. Jeevalakshmi, D., Narayana Reddy, S. and Manikiam, B., Land surface temperature retrieval from LANDSAT data using emissivity estimation. Int. J. Appl. Eng. Res., 2017, 12, 9679-9687.

15. United States Geological Survey, Landsat 8 (L8) Data Users Handbook, USGS, EROS, Sioux Falls, South Dakota, April 2019.

16. Sobrino, J. A., Jimenez-Munoz, J. C. and Paolini, L., Land surface temperature retrieval from Landsat TM 5. Remote Sensing Environ., 2004, 90(4), 434-440.

17. Sobrino, J. A. and Raissouni, N., Towards remote sensing methods for land cover dynamic monitoring: application to Morocco. Int. J. Remote Sensing, 2000, 21(2), 353-366.

18. Garain, S., Mitra, D. and Das, P., Detection of hydrocarbon microseepage-induced anomalies by spectral enhancements of Landsat 7 ETM+ images in part of Assam-Arakan Fold Belt, India. J. Pet. Explor. Prod. Technol., 2019, 9, 2573-2582; doi.org/10.1007/ s13202-019-00747-w.

ACKNOWLEDGEMENTS. We thank the Indian Institute of Remote Sensing, Dehradun, and the Department of Applied Geology, Indian Institute of Technology (Indian School of Mines), Dhanbad, for the providing necessary infrastructures and analytical facilities. We also thank the USGS EROS Data Center for the necessary satellite images that were freely downloaded. The views expressed here are those of the authors and do not reflect the organizations they belong to.

Received 31 December 2019; revised accepted 22 May 2020

doi: $10.18520 / \mathrm{cs} / \mathrm{v} 119 / \mathrm{i} 1 / 128-133$ 